\title{
Dipicolinic Acid as an Antioxidant: Protection of Glutathione Reductase from the Inactivation by Copper
}

\author{
Keiko Murakami and Masataka Yoshino \\ Department of Biochemistry, Aichi Medical University, Nagakute, Aichi 480-1195, Japan \\ (Received 18 December 1999; and accepted 31 December 1999)
}

\begin{abstract}
Glutathione reductase from yeast was markedly inactivated by cuprous ion and to a lesser extent by cupric ion. Dipicolinic acid protected glutathione reductase from the inactivation by copper, whereas other pyridine carboxylic acids including picolinic acid and quinolinic acid did not show any protective effect. Reduction by ascorbate of cupric ion to cuprous ion, an inactivating agent having greater potency, was completely inhibited by dipicolinic acid. Dipicolinic acid also reversed the inhibition by copper of the reduced glutathione formation in permeabilized yeast cells. Copper causes oxidative damages to cells by inactivating glutathione reductase, which plays a principal role in regenerating reduced glutathione used as a scavenger of reactive oxygen species. Dipicolinic acid may act as an antioxidant by protecting glutathione reductase from the inactivation by copper.
\end{abstract}

Glutathione reductase (EC 1.6.4.2) catalyzes the NADPH-dependent reduction of glutathione disulfide (GSSG). The enzyme is responsible for maintaining glutathione in the reduced state. By coupling with glutathione peroxidase (EC 1. 11. 1. 9), glutathione reductase participates in preventing cellular damage caused by oxygen radicals (16). Analyses of the regulation of glutathione reductase are essential for understanding the antioxidant system. Several metal cations such as $\mathrm{Cd}^{2+}$ and $\mathrm{Cu}^{2+}$ inhibit glutathione reductase, and may contribute to the oxidative damage to cells by inhibiting GSH regeneration $(1,13)$. However, the defense or protection mechanism against the inhibition of glutathione reductase reaction has remained unknown. In this paper we analyze the protective action of

Address for correspondence: Dr Masataka Yoshino Department of Biochemistry, Aichi Medical University, Nagakute, Aichi 480-1195, Japan

Tel: +81-52-264-4811

Fax: +81-561-61-4056

E-mail: yoshino@aichi-med-u.ac.jp dipicolinic acid (pyridine 2,6-dicarboxylic acid) on the copper-mediated inactivation of glutathione reductase. We showed previously (10) that dipicolinic acid, biosynthesized by some microorganisms, especially genus Bacillus (17), exerts an inhibitory effect on lipid peroxidation. Dipicolinic acid may act as an antioxidant by enhanced regeneration of reduced glutathione, in addition to the inhibition of lipid peroxidation.

\section{MATERIALS AND METHODS}

\section{Materials}

The sources of materials used in this work were as follows: Saccharomyces cerevisiae glutathione reductase $(170 \mu \mathrm{mol} / \mathrm{min}$ per $\mathrm{mg}$ protein) from Oriental Yeast Co. (Tokyo, Japan), oxidized and reduced glutathione from Sigma-Aldrich-Japan (Tokyo, Japan), NADP and NADPH from Boehringer-Mannhaim-Yamanouchi (Tokyo, Japan), and dipicolinic acid, quinolinic acid and picolinic acid from Tokyo Fine Chemical Co. (Tokyo, Japan). Baker's yeast (Saccharomyces cerevisiae) was purchased locally. 


\section{Determination of Glutathione Reductase}

The glutathione reductase activity was determined spectrophotometrically at $37^{\circ} \mathrm{C}$ by following decrease in the absorbance of NADPH at 340 $\mathrm{nm}$. Reaction mixture of $1 \mathrm{~mL}$ comprised $50 \mathrm{mM}$ Tris- $\mathrm{HCl}(\mathrm{pH} 7.1), 0.1 \mathrm{mg}$ of the purified enzyme and various concentrations of oxidized glutathione, NADPH and metal cations as chloride or sulfate salts.

\section{Reduction of $\mathrm{Cu}^{2+}$ ion by ascorbate}

The reaction mixture of $0.4 \mathrm{~mL}$, composed of 10 $\mathrm{mM}$ Tris- $\mathrm{HCl}(\mathrm{pH} 7.1), 0.05 \mathrm{mM} \mathrm{CuSO}_{4}$, various concentrations of ascorbate and $1 \mathrm{mM}$ pyridine carboxylates, was incubated at $37^{\circ} \mathrm{C}$ for $10 \mathrm{~min}$. Then $\mathrm{Cu}^{+}$ion formed was determined by adding $0.5 \mathrm{mM}$ bathocuproine disulfonate, followed by measurement of absorbance at $492 \mathrm{~nm}$.

\section{Reduction of oxidized glutathione in permeabil- ized yeast cells}

Yeast cells were permeabilized with toluene (9). Permeabilized yeast cells ( $1 \mathrm{mg}$ packed weight/ $\mathrm{mL}$ ) were incubated at $37^{\circ} \mathrm{C}$ with $0.5 \mathrm{mM}$ oxid- ized glutathione, $0.2 \mathrm{mM}$ NADP, $0.2 \mathrm{mM}$ threo-

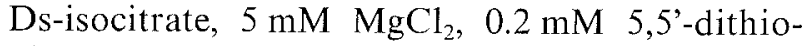
bis(2-nitrobenzoic acid), $5 \mathrm{mM}$ ascorbic acid and various pyridine caroboxylic acid at $0.1 \mathrm{mM}$ in 1 $\mathrm{mL}$ of $40 \mathrm{mM}$ Tris- $\mathrm{HCl}$ ( $\mathrm{pH} 7.1$ ). The formation of reduced glutathione was followed by the increase in absorbance at $412 \mathrm{~nm}$.

\section{RESULTS}

Formation of reduced glutathione with purified glutathione reductase was linear with time, but addition of copper caused a time-dependent and dose-dependent inactivation of the enzyme (Fig. 1). Cuprous ion showed a potent inactivating effect (Fig. 1A), and then cupric ion also inactivated the enzyme to a lesser extent (Fig. 1B). When EDTA was added $100 \mathrm{~s}$ after the initiation of the reaction in the presence of copper, activity of the enzyme recovered (Fig. 2).

We examined the effect of the increasing copper concentrations on the enzyme inactivation. The concentration of cuprous ion required for $50 \%$ inactivation of the enzyme was $0.15-0.2 \mu \mathrm{M}$ (Fig. $3 \mathrm{~A})$. The inactivation by cupric ion was rather weak, the concentration required for $50 \%$ inactivation being 2 to $3 \mu \mathrm{M}$ (Fig. 3B). We also
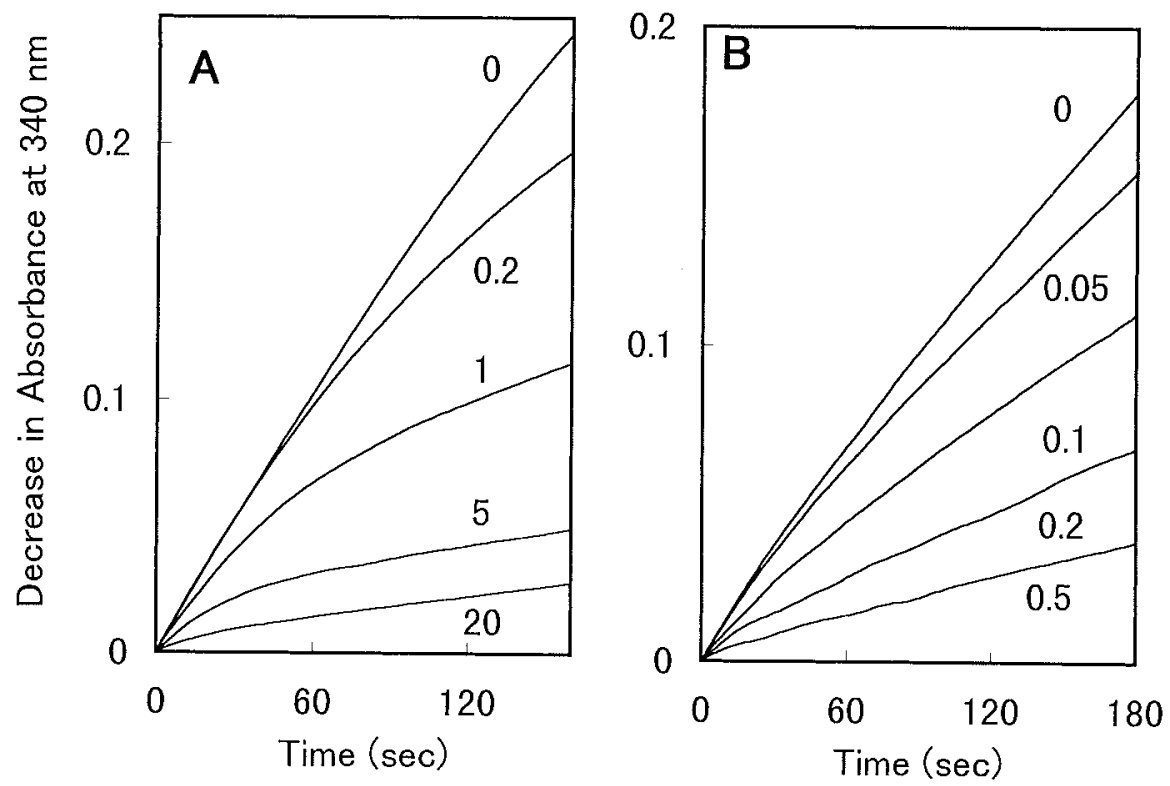

Fig. 1 Time course of the glutathione reductase reaction in the presence of copper ion. Reaction mixture contained $0.5 \mathrm{mM}$ oxidized glutathione, $0.15 \mathrm{mM} \mathrm{NADPH}$, purified glutathione reductase $(0.1 \mathrm{mg})$ and various concentrations of $\mathrm{CuSO}_{4}$ in the absence (A) and presence of $0.5 \mathrm{mM}$ ascorbate (B). The activity was followed by the decrease in absorbance at $340 \mathrm{~nm}$. Concentrations of cuprous and cupric ions included were indicated $\mu \mathrm{M}$ along the lines. A. Effect of cupric ion. B. Effect of cuprous ion (reduced with ascorbate). 


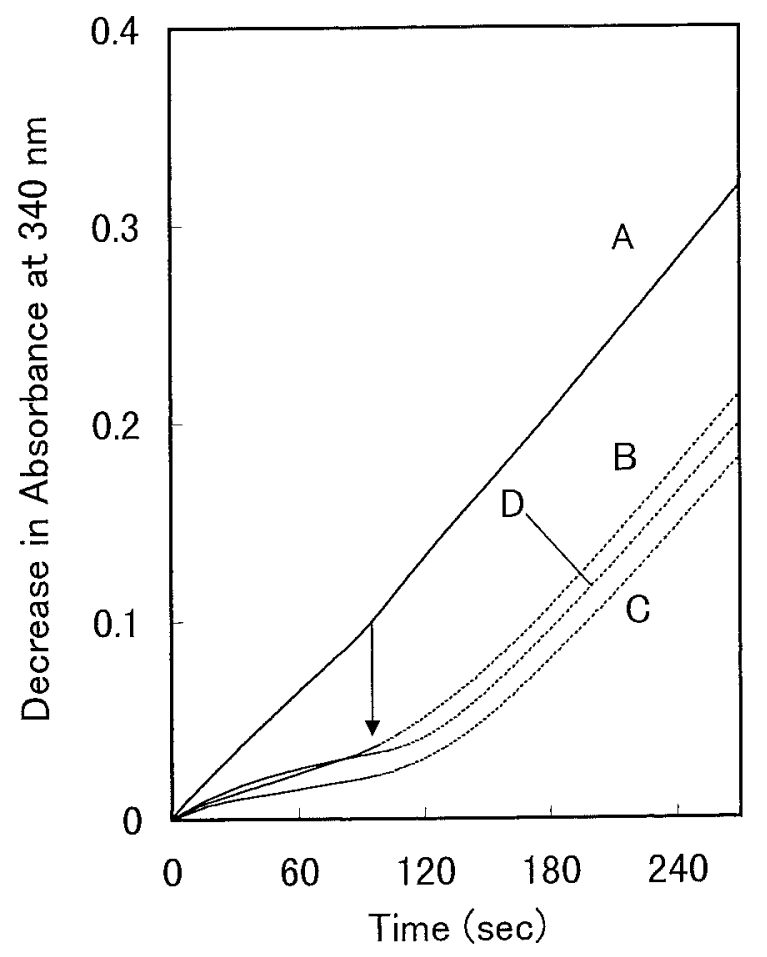

Fig. 2 Effect of EDTA on the inactivation by copper of glutathione reductase. Reaction mixture was similar to that described in the legend to Fig. 1, except that the copper concentrations were $0.2,1.0$ or $10 \mu \mathrm{M}$ in the absence or presence of ascorbate. EDTA $(0.2 \mathrm{mM})$ was added to the mixture $100 \mathrm{sec}$ after the initiation of the reaction (indicated by the arrow). Curve A, control (no metal) without addition of EDTA. Curve B, $0.2 \mu \mathrm{M} \mathrm{CuSO}_{4}$ plus $0.5 \mathrm{mM}$ ascorbate. Curve $\mathrm{C}, 1 \mu \mathrm{M} \mathrm{CuSO}_{4}$ plus $0.5 \mathrm{mM}$ ascorbate. Curve D, $10 \mu \mathrm{M} \mathrm{CuSO}_{4}$ without ascorbate.

examined the effect of various pyridine carboxylic acids on the enzyme inactivation. Of the pyridine carboxylic acids tested, dipicolinic acid effectively protected glutathione reductase against the inactivation by $\mathrm{Cu}^{+}$, whereas quinolinic acid and picolinic acid exhibited no effect (Fig. 3A). Inactivation of the enzyme by $\mathrm{Cu}^{2+}$ ion was also considerably prevented by dipicolinic acid, but quinolinic acid and picolinic acid showed only a little protective effect (Fig. 3B).

Protective effect of increasing concentrations of dipicolinic acid on the inactivation by $\mathrm{Cu}^{+}$ and $\mathrm{Cu}^{2+}$ of glutathione reductase is shown in Fig. 4. The concentration of dipicolinic acid necessary for $50 \%$ protection of the enzyme against the inactivation was about $10 \mu \mathrm{M}$.

Ascorbate reduced cupric ion to cuprous ion,
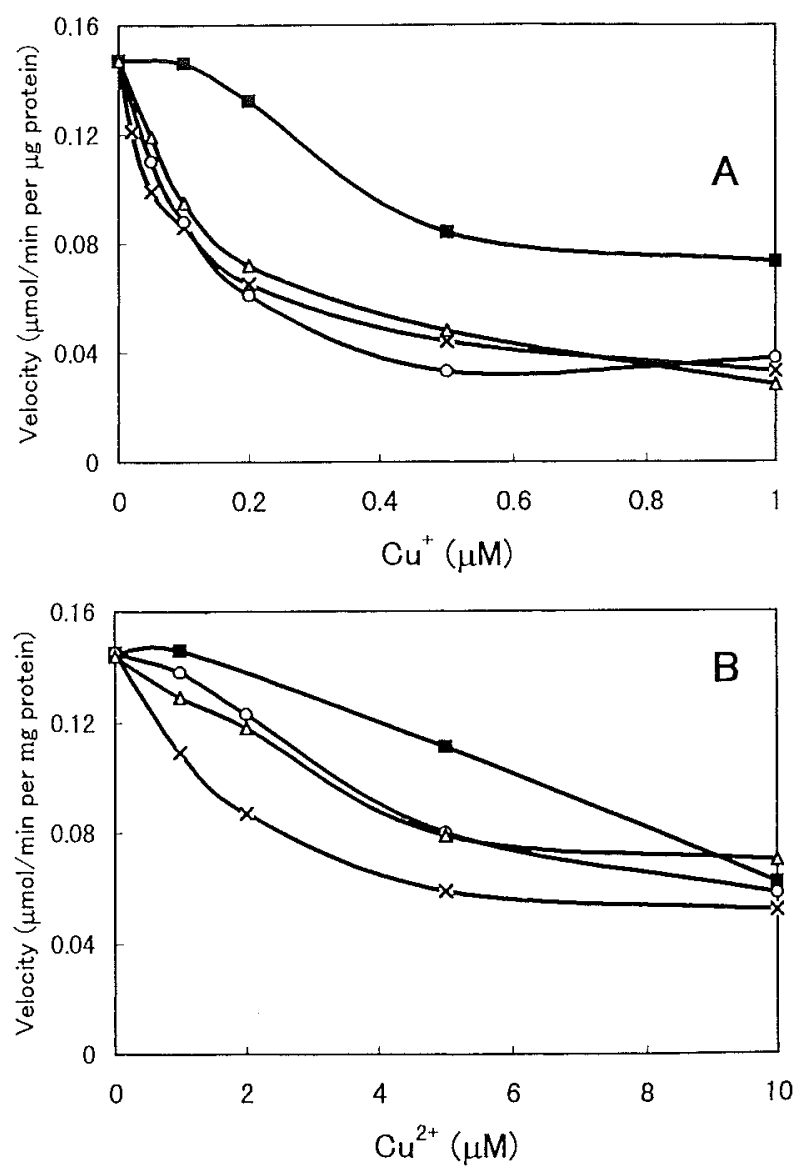

Fig. 3 Inactivation of glutathione reductase by copper ions and its protection by pyridine carboxylates. Reaction conditions were similar to those of Fig. 1, except that pyridine carboxylates $(0.1 \mathrm{mM}$ each $)$ were included in the mixture. The activity was determined after preincubation with copper and pyridine carboxylates for $2 \mathrm{~min}$. A. Inactivation by cuprous ion ( $\mathrm{CuSO}_{4}$ plus ascorbate). B. Inactivation by cupric ion (without ascorbate). $\times$, None; $\boldsymbol{\square}$, Dipicolinic acid; $O$, Picolinic acid; $\triangle$, Quinolinic acid.

the agent having more potent inactivation on glutathione reductase. Effect of pyridine compounds on the reduction of copper by ascorbate was examined. Dipicolinic acid completely inhibited the copper reduction. However, picolinic acid and quinolinic acid showed only a little inhibitory effect on the copper reduction (Fig. 5).

Effect of pyridine carboxylic acids on the formation of reduced glutathione was examined on yeast cells in situ. Addition of copper as a form of cuprous ion markedly inhibited the reduction of oxidized glutathione in the permeabilized yeast cells. Dipicolinic acid effectively reversed the 


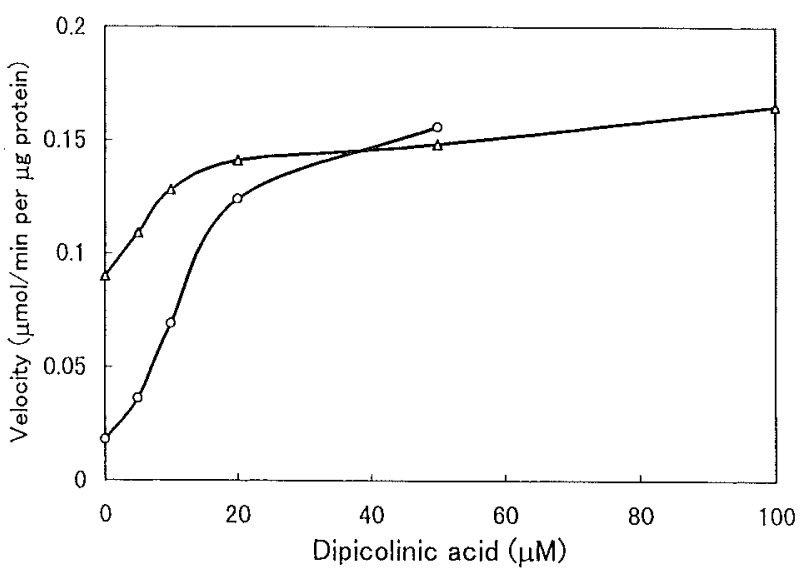

Fig. 4 Protective effect of dipicolinic acid on the inactivation by copper of glutathione reductase. Reaction mixture was similar to that of Fig. 1, except that copper concentrations were kept at 0.2 $\mu \mathrm{M} \mathrm{CuSO}{ }_{4}$ with $0.5 \mathrm{mM}$ ascorbate $(\bigcirc)$ and 1 $\mu \mathrm{M} \mathrm{CuSO}_{4}$ without ascorbate $(\triangle)$ in the presence of various concentrations of dipicolinic acid. Activity was determined after preincubation with copper and dipicolinic acid for $2 \mathrm{~min}$.

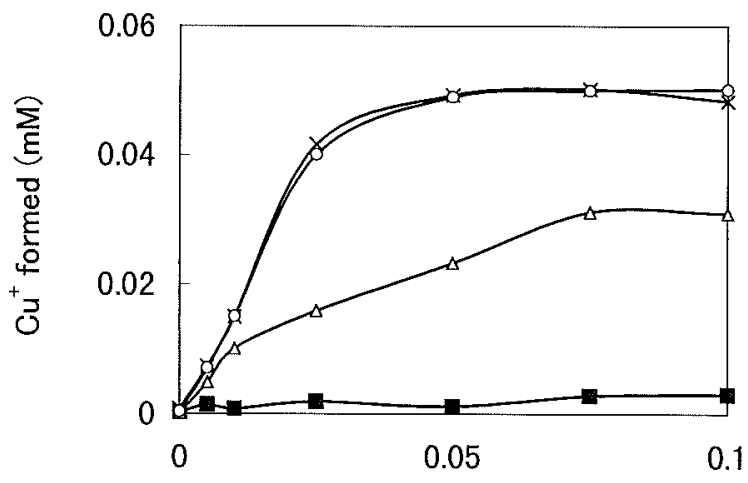

Ascorbic acid (mM)

Fig. 5 Effect of dipicolinic acid on the reduction by ascorbate of copper. Reaction mixture $(0.4 \mathrm{~mL})$ containing $0.05 \mathrm{mM} \mathrm{CuSO}_{4}$, various concentrations of ascorbate, and $1 \mathrm{mM}$ pyridine carboxylates in 10 $\mathrm{mM}$ Tris- $\mathrm{HCl}$ ( $\mathrm{pH} \mathrm{7.1),} \mathrm{was} \mathrm{incubated} \mathrm{at} 37^{\circ} \mathrm{C}$ for 10 min. Reduced copper was then determined by the addition of $1 \mathrm{mM}$ bathocuproine disulfonate as described in Materials and Methods. $x$, None; $\mathbf{\square}$, Dipicolinic acid; $\bigcirc$, Picolinic acid; $\triangle$, Quinolinic acid.

inhibition by $\mathrm{Cu}^{+}$of the reduced glutathione formation, whereas quinolinic acid and picolinic acid did not show any protective effect (Fig. 6).

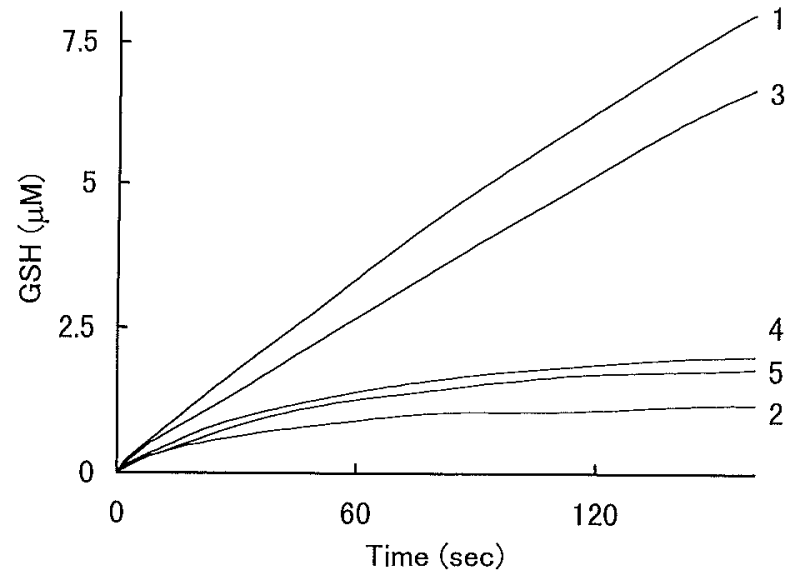

Fig. 6 Effect of pyridine carboxylates on the inactivation by copper of the regeneration of reduced glutathione in permeabilized yeast cells. Yeast cells $(1 \mathrm{mg} / \mathrm{mL})$ permeabilized with toluene (9) were incubated at $37^{\circ} \mathrm{C}$ with $0.5 \mathrm{mM}$ oxidized glutathione, $0.2 \mathrm{mM}$ NADP, $0.2 \mathrm{mM}$ threo-Ds-isocitrate, 5 $\mathrm{mM} \mathrm{MgCl}_{2}, 0.2 \mathrm{mM}$ 5,5'-dithio-bis(2-nitrobenzoic acid), $5 \mathrm{mM}$ ascorbic acid and various pyridine carboxylic acid of $0.1 \mathrm{mM}$ in $40 \mathrm{mM}$ Tris-HCl buffer ( $\mathrm{pH}$ 7.1). The formation of reduced glutathione was followed by increase in the absorbance at $412 \mathrm{~nm}$. Curve 1, None; Curve 2, $10 \mu \mathrm{M} \mathrm{CuSO}_{4}$ plus $5 \mathrm{mM}$ ascorbic acid added; Curve $3,0.1 \mathrm{mM}$ dipicolinic acid plus $\mathrm{CuSO}_{4}$ /ascorbate added; Curve 4,0.1 mM picolinic acid plus $\mathrm{CuSO}_{4}$ /ascorbate added; Curve 5, $0.1 \mathrm{mM}$ quinolinic acid plus $\mathrm{CuSO}_{4} /$ ascorbate added.

\section{DISCUSSION}

Biological toxicity of copper is closely related to the oxidative damage to cells by reactive oxygen species (14). Copper is a transition metal and has the ability to undergo valence changes, and it would be expected to promote generation of reactive oxygen species through the interaction with oxygen molecule (2). The superoxide radical, $\mathrm{O}_{2}^{-}$, generated by one-electron reduction of oxygen molecule by transition metals, is largely dismuted into hydrogen peroxide, which can be converted to highly reactive hydroxyl radical by the metal-catalyzed Fenton reaction (4). Since these reactive oxygen species act as an actual initiating species for cellular oxidative injury (6), various antioxidant mechanisms should be operative for scavenging oxygen radicals (5). Glutathione plays a principal role in the antioxidant system, and glutathione reductase is responsible for the regeneration of reduced glutathione util- 
ized as an essential substrate for glutathione peroxidase reaction (17). Inhibition or inactivation of these antioxidant enzymes causes oxidative damage to cells. For example, inactivation and fragmentation of superoxide dismutase by hydrogen peroxide can disrupt the antioxidant system (11). Inactivation of glutathione peroxidase enhances oxidative injuries by reactive oxygen species (3). The inactivation by copper ion of glutathione reductase may cause the cellular oxidative damage by inhibiting regeneration of reduced glutathione, a principal scavenger of reactive oxygen species.

Of particular interest is the finding on the protection of copper-mediated inactivation of glutathione reductase by dipicolinic acid. $\mathrm{Cu}-$ prous ion is known to bind preferentially to sulfhydryl groups (7) and thereby to cause potent inactivation of glutathione reductase. Dipicolinic showed a marked protective effect on the cuprous ion-mediated inactivation of glutathione reductase. Dipicolinic acid and other pyridine carboxylates have large stability constants with most metals $(7,12)$, but the protective effect of dipicolinic acid cannot be ascribed to merely the chelation of copper, because only dipicolinic acid showed the protection. When dipicolinic acid with a high degree of electron-deficient character binds $\mathrm{Cu}^{+}$ion, it can enhance attraction of an electron from $\mathrm{Cu}^{+}$to form $\mathrm{Cu}^{2+}$ ion, the less potent inactivating copper (10), resulting in the protection of glutathione reductase from the modification of $\mathrm{SH}$ groups and inactivation by $\mathrm{Cu}^{+}$. Other pyridine carboxlates such as quinolinic acid with less electron-deficient nature showed no ability of oxidizing $\mathrm{Cu}^{+}$to $\mathrm{Cu}^{2+}(10)$, and thus, no protective effect on the $\mathrm{Cu}^{+}$mediated inactivation of the enzyme. On the other hand, cupric ion binds to amino and carboxyl groups in addition to the SH groups (7), resulting in rather weak inactivation of the enzyme. Protective effect of pyridine carboxylates on the inactivation by $\mathrm{Cu}^{2+}$ of glutathione reductase can be ascribed to the chelation of $\mathrm{Cu}^{2+}$ ion. Thus, marked difference in the protective effect cannot be observed between dipicolinic acid and quinolinic acid.

Protection of glutathione reductase and the inhibition of the reduction by ascorbate of cupric to cuprous ion by dipicolinic acid imply that this pyridine dicarboxylic acid contributes to the antioxidant defense mechanism. Dipicolinic acid is abundant in bacterial spores, especially those of genus Bacillus (17), and a habit in Japan of eating Natto, a traditional fermented food made from soybeans with Bacillus may cause intake of a large amount of dipicolinic acid (15). Recently, we showed that dipicolinic acid inhibits lipid peroxidation and protects the inactivation by hydroxyl radical of AMP deaminase (10). Dipicolinic acid can act as an antioxidant by the protection of glutathione reductase, a principal antioxidant enzyme, from the metal-dependent inactivation, and by scavenging reactive oxygen species.

\section{Acknowledgements}

This work was supported in part by Grant-in-Aid for Scientific Research (C) (No.09670163) from the Ministry of Education, Science, Sports and Culture of Japan, and by a research grant from the Urakami Foundation.

\section{REFERENCES}

1. Acan, N. L. and Tezcan, E. F. (1995) Inhibition kinetics of sheep brain glutathione reductase by cadmium ion. Biochem. Mol. Med. 54, 33-37.

2. Aust, S. D., Miller, D. M. and Samokyszyn, V. M. (1990) Iron redox reactions and lipid peroxidation. Methods Enzymol. 186, 457-463.

3. Blum, J. and Fridovich, I. (1985) Inactivation of glutathione peroxidase by superoxide radical. Arch. Biochem. Bioplys. 240, 500-508.

4. Fridovich, I. (1995) Superoxide radical and superoxide dismutases. Annu. Rev. Biochem. 64, 97-112.

5. Halliwell, B. (1995) Antioxidant characterization. Methodology and mechanism. Biochem. Pharmacol. 49, 13411348.

6. Halliwell, B. and Gutteridge, J. M. C. (1990) Role of the radicals and catalytic metal ions in human disease: An overview. Methods Enzymol. 186, 1-85.

7. Jocelyn, P. C. (1972) In Biochemistry of the SH Group. pp.63-93. Academic Press, New York.

8. Martin, B. L. (1997) Selective activation of calcineurin by dipicolinic acid. Arch. Biochem. Biophys. 345, 332-3382.

9. Murakami, K., Nagura, H and Yoshino, M. (1980) Permeabilization of yeast cells: Application to study on the regulation of AMP deaminase activity in situ. Anal. Biochem. 105, 407-413.

10. Murakami, K., Ueda, T., Morikawa, R., Ito, M., Haneda, M. and Yoshino, M. (1998) Antioxidant effect of dipicolinic acid on the metal-catalyzed lipid peroxidation and enzyme inactivation. Biomedical Res. 19, 205-208.

11. Ookawara, T., Kawamura, N., Kitagawa, Y. and Taniguchi, N. (1992) Site-specific and random fragmentation of $\mathrm{Cu}, \mathrm{Zn}$-superoxide dismutase by glycation reaction. Implication of reactive oxygen species. J. Biol. Chem. 267, $18505-18510$.

12. Pocker, Y. and Fong, C. T. O. (1980) Kinetics of inactivation of erythrocyte carbonic anhydrase by sodium 2,6pyridine dicarboxylate. Biochenistry. 19, 2045-2050. 
13. Serafini, M. T., Romeu, A. and Arola, L. (1989) Zn(II), $\mathrm{Cd}(\mathrm{II})$ and $\mathrm{Cu}(\mathrm{II})$ interactions on glutathione reductase and glucose-6-phosphate dehydrogenase. Biochem. Int. 18, 793-802.

14. Shinar, E., Navok, T. and Chevion, M. (1983) The analogous mechanisms of enzymatic inactivation induced by ascorbic and superoxide in the presence of copper. $J$. Biol. Chem. 258, 14778-14783.

15. Wang, J. and Fung, D. Y. (1996) Alkaline-fermented foods: a review with emphasis on pidan fermentation. Crit. Rev. Microbiol. 22, 101-138.

16. Williams, C. H. Jr. (1976) Flavin containing dehydrogenases. In The Enzymes (Boyer D. P. ed.) 3rd edn. vol.13, pp.89-173, New York, Academic Press.

17. Woodruff, W. H., Spiro, T. G. and Gilvarg, C. (1974) Raman spectroscopy in viro: Evidence on the structure of dipicolinic acid in intact spores of Bacillus megaterium. Biochem. Biophys. Res. Commun. 58, 197-203. 